InUITED REUIEW BASIC MEDICAL SCIENCES

กORTH CLIn IStanB 2018;5(4):379-386

doi: $10.14744 /$ nci.2018.68815

\title{
How to get ethics committee approval for clinical trials in Turkey?
}

\author{
(1D) Hilal Ilbars, ${ }^{1}$ (1) Berna Terzioglu Bebitoglu² \\ ${ }^{1}$ Turkish Medicines and Medical Devices Agency, Ankara, Turkey \\ 2Department of Medical Pharmacology, Istanbul Medeniyet University Faculty of Medicine, Istanbul, Turkey
}

\begin{abstract}
The "ethics committee approval" required to conduct clinical trials can be difficult to obtain for researchers due to problems with their time management, evaluating clinical investigations as a routine process as a part of their work; confusions regarding the concepts of treatment, interference, research and intervention, and sometimes due to lack of knowledge. Ethics committee approval process in our country is discussed by informing the investigators who want to conduct clinical research, about the issues that should be considered in accordance with the current legal regulations related to the clinical trials involving human volunteers.
\end{abstract}

Keywords: Ethics committee; clinical trial; Turkey.

Cite this article as: Ilbars H, Terzioglu Bebitoglu B. How to get ethics committee approval for clinical trials in Turkey? North Clin Istanb 2018;5(4):379-386.

$\mathrm{I}^{\mathrm{n}}$ $\mathrm{n}$ this paper, within the frame of current legal regulations in Turkey, we mentioned about some issues which should be paid attention by those who want to conduct clinical trials, and discuss the ways of obtaining ethics committee approval.

To obtain "ethics committee approval" required to conduct clinical researches can be difficult for researchers due to problems with their time management, evaluating clinical investigations as a part of their routine work; confusions regarding the concepts of treatment, interference, research and intervention, and sometimes due to lack of knowledge.

Sometimes a critical perspective may be displayed against members of ethics committees. Ethics committees specified as "independent committees established to give scientific and ethical opinion about the trial to protect rights, safety and well-being of participants who are willing to participate in the trial" [1-3].

Why do we participate in clinical trials? Why there are so many documents and rules? First of all, we need to understand the answers to these questions. The researcher may participate in clinical trials to gain experience about current applications, to have international recognition, to be able to follow studies performed in international area, to prepare his/her specialty thesis, to contribute to science, and to gain early access into new scientific information. From the perspective of participants, they wish to reach earlier to new information, researches, and treatment alternatives, to be able to be followed up by his/her physician more closely, and to lower his/her healthcare costs because the sponsors cover expenses of many required tests, examinations, and treatments [4].

Before starting to perform a new clinical trial, the researchers should apply to the ethics committee, and should know some concepts related to ethical rules, clinical trial regulations, ethical rules, and how to access them.

Primarily one should discriminate between the conceptsof "treatment"with"research",and"interference"with 
"intervention". Turkish Linguistic Society defined these terms as follows [5];

Treatment: 1 . noun: to cure or mitigate the disease using various methods, management, therapy

2. dealing with an issue in an attempt to correct or improve it

Research: 1, noun: the act of investigating, search, examination, inspection

2. methodological study in the field of science and art, investigation

Interference: 1 , noun: undertaking, enterprise, attempt

2. physics: the process of coming together of two or more than two waves to the same point with resultant reinforcement or cancellation each other (interference).

Some definitions found in the Dictionary of Medical Terms: Intervention: Interference, interposition, involvement; the approach of a psychoanalyst to a patient with suggestions so as to resolve his/her psychological problem. In psychiatry, the physician's interference with the mental world of the patient so as to effect his/her way of conduct or thinking. The acts of a living creature aiming to change its environment or its relations with it [6].

Medical Intervention: Any kind of activity realized by legally authorized health professionals so as to diagnose, treat any physical and/or mental deficiency, disorder or disease, if not possible alleviate, prevent its progression, and worsening, its potential complications to be manifest in the future, and relieve pain in compliance with general rules, and principles demanded by the science of medicine.

Medical intervention aims to protect health of an individual from harm, essentially it is directed at physical integrity of a person. This approach determined the relation between the physician, and the patient. Enlightment is the debt to be paid by the physician, but it is a right for a patient.

Since each intervention performed by the physician will be illegal if informed consent of the patient is not obtained priorly, informed consent of the patient is the basic prerequisite for the compliance of medical intervention with relevant laws.

Both the researhers and ethics committe members should know these terminology well and use them correctly and evaluate the study by knowing the Turkish equivalents of the English terms "invasive" and "intervention".

The researchers should not think that there is no need for gathering information, and submitting and documents such as budget, and ethics committee approval with the thought of "the study participant would already receive this treatment", or "these interventions will be applied anyhow", These concepts should be differentiated from each other, and essentials of legal regulations implemented in Turkey should be known even though not in detail.

It is possible to access into regulations concerning clinical trials in Turkey from following links: www.mevzuat. gov.tr; www.resmigazete.gov.tr; www.titck.gov.tr.

In general, some Laws, International Contracts, Regulations, Implementing Regulations, Legislations, Directives, Circular, Guidelines, Guiding documents and related articles are indicated in Table 1 [7-10].

It is obvious that researchers in Turkey do not know exactly where to apply for ethics committe approval and how to apply, which documents are required [11].

According to current regulations there exists three different ethics committee; "Clinical Trials Ethics Committee", "Bioavailability/Bioequivalence Ethics Committee" and "Ethics Committees of Cosmetic Clinical Research Studies". Apart from these, the "Ethics Committee of Non-Interventional Studies", whose name is contraversial, is available in many academic institutions and often gives approval even for those interventional studies according to legislation that should be approved by "Clinical Trial Ethics Committee". Besides, there are many boards with names "Ethics committee of clinical trials with non-pharmaceutical products", "Ethics commissions", that provide ethics committee approvals for clinical researches with human volunteers. However as stated above only three ethics committees evaluate researches covered by relevant regulations. The locations of ethics committees can be found in the website "www. titck.gov.tr". However this website should be updated with links of ethics committees and their updated contact information.

According to the "Health Services Fundamental Law" Article 10-(Annex: 6/4/2011-6225/8) (Amended section: 2/1/2014-6514/45); "use of any treatment method or tools or even approved and licenced drugs, and their preparations, medical, and biological products, herbal products, cosmetics products, and their raw materials, and medical devices, on human beings with the intention of scientific research requires approvals granted by Ministry of Health and affiliated establishments........" for the use of each indicated item necessitates interim arrangements. Currently, regulations concerning drugs, medical, and biological products, cosmetics products, 
TABLE 1. Legal regulations, and guide documents concerning clinical researches in our country
Law, $\quad$ Constitution (item 17)
international - Human Rights, and Biomedicine Convention
conventions, - - The Law on the Practice of Medicine and Medical Sciences (issue no: 14/04/1928-863: item no: 70)
legislations - Fundamental Law on Health Services Amendment no:10
- Turkish Criminal Law (2004/Amended 2005 -issue no: 5237: item no: 90)
- Protection of Personal Data Act (6698) (04/07/2016-issue no: 29677)
- Medical Deontology Legislation (19/02/1960-10436 issue no: items: 10 and 11)
Regulations - Regulation of Clinical Investigations with Drugs and Biological Products
- Regulation on Clinical Trials on Medical Devices
- Regulation on Traditional and Complementary Medicine Practices (27/10/2014-29158)
- Regulation on Processing and Protecting The Privacy of Personal Health Data (20/10/2016-29863)
- Regulation on Clinical Researches on Effectiveness and Safety Studies on Cosmetic Products and their Raw Materials
Guidelines - Good Clinical Practices Guideline
- Guideline for Observational Drug Studies
- Guideline for the Application to Ethics Committees for Clinical Researches, and Bioavailability-Bioequivalency Studies
- Procedure of Application to Directorate of Department of Clinical Researches of Turkish Medicines, and Medical Devices Agency
- Standard Working Procedures of Ethics Committees for Clinical Researches, Bioavailability-Bioequvalence Studies
- Guideline for Ethical Approaches to Clinical Trials Conducted in Pediatric Population
- Guideline for Essentials, and Principles of Good Clinical Practices applied for Advanced Treatment Products
- Guideline for the Management of Biological Materials in Clinical Researches
- Guideline for the Insurance Coverage to be Performed in Clinical Trials
- Guideline for Reports on Safety Issues in Clinical Trials
- Guideline for Reports on Development, Safety, Updating in Clinical Trials
- Guideline for The Application to The Assembly ofClinical Researchers
- Guideline for Principles of Programming and Evaluating of Training in ClinicalTrials
- Guideline for The Essential Principles of Central Organization Management in Clinical Trials
- Guideline for Independent Data Monitoring Committee
- Guideline for The Structure, and Essential Principles of Procedures, and Principles of Bioethics Committee
- Guideline on the Essentials of The Standard Working Method of Advisory Committee of Clinical Trials
- Guideline for the Storage, and Distribution of Investigational Products used in Clinical Trials
- Guideline for Principles of Archiving in Clinical Trials
- Guideline for Efficacy, and Safety Trialsof Cosmetic Products or Raw Materials performed with Volunteers
Other - Declaration of Helsinki
documents - ISO 14155-1/2 Clinical Investigation of Medical Devices for Human Volunteers
- In vitro evaluation of the Performance of Medical Diagnostic Device \#EN13612
- Medical development documents
- http://ec.europa.eu/health/medical devices/documents/guidelines/index_en.htm

and medical devices have been published, however regulations concerning other provisions indicated in the law should be made.

Though it has not been indicated clearly in any legislation right now, basically for the following investigations only ethics committee approval is sufficient for initiation and conduct of the study;

- Retrospective studies,

- Investigations to be performed concerning stem cell, blood, urine, and tissue samples, hair, saliva, gaita, radiological images, biochemical, microbiological, pathological materials, provided that the treatment 
received by the diseased volunteers is not changed or interfered or that the healthy volunteers is not applied a new treatment or application.

- Investigations on body physiology,

- Cell culture, and tissue culture studies,

- Investigations based on anthropometric measurements,

- Investigations using questionnaires, and similar data collection tools, and assessments of life-style which are performed without interfering directly with lives of human beings.

Including bioavailability and bioequivalence studies, all clinical studies that will be conducted on human beings, with drugs, medical, and biological products, herbal products, cosmetic products, and their raw materials, even licensed or received permission, medical devices, and surgical studies, stem cell studies, and clinical investigations where a treatment or an intervention will be directly performed, require approvals of both ethics committee, and Ministry of Health or affiliated institutions as deemed necessary by Health Services Fundamental Law. However, working of new regulations regarding these were started and its publication will guide the researchers.

When investigations will be performed with materials obtained from human body, it is helpful to emphasize these statements; in compliance with both "Biomedicine Contract;SectionV.-ScientificResearchandSectionVIIProhibitionofDispositionandCommercialGainonParts ExtractedfromHumanBody,andArticle22-Disposition on Parts Extractedfrom Human Body; When any part of the human body is removed, this part may be saved and used only if appropiate informed consent is obtained and can be kept and used for other than the intention for its removal." and also "Helsinki Declaration; Article 32-For use of material, and data kept in biobanks, and similar storage places whose identity can be determined, the physician should obtain the approval for collection, analysis, storage and/or reuse for a medical investigation. If it is impossible or impractical to obtain this approval for the investigation, the research can be performed after evaluation and approval of a research ethics committee".

Investigations concerning drugs, medical, and biological products

Development of drugs, and medical products are examined in specified phases. The candidate molecule should be tested in preclinically in vitro, and in vivo experiments, and after confirmation of its efficacy, and safety, its trials in human beings should be performed in centers where required conditions are fulfilled, and controlled. Phases of clinical product development are summarized in Table 2.

Legal obligations regarding clinical trials that will be performed on human subjects in our country was established in "Regulation of Clinical Trials" published in the Official Gazette (date: 13/4/2013, issue no: 28617; amendment: date: 25/6/2014; issue no: 29041). Article 2-(1) (Amendment: RG-25/6/2014-29041) stipulates that: "This Regulation applies to clinical trials conducted in humans, including studies to investigate bioavailability and bioequivalence, with drugs, medicinal and biological products, or herbal medicinal products, whether authorized or licensed, as well as the centers where clinical trials are conducted, and the natural or juristic persons who conduct them. (2) Retrospective studies are not covered by this Regulation.

In the same regulation, the centers eligible for conducting trials have been specified as follows: "Clinical trials may only be conducted at centers for health practice and research established within universities, approved centers for research and development subordinate to universities. Clinical trials conducted at centers mentioned above may be supplemented with other health institutions or organizations meeting the criteria specified herein, provided it will be under coordination and responsibility of these centers."

Phase I and bioavailability and bioequivalence studies can be performed in health institutions, and organizations, and research centers authorized by Turkish Medicines and Medical Devices Agency (TITCK) and affiliated with the Ministry of Health or universities which have facilities convenient for application of emergency interventions, and standards individually specified for each center. The centers are published, and updated in the website of TITCK.

\section{Sending samples abroad}

"Regulations on Medical Laboratories" published in the Official Gazette (date: 9/10/2013, issue no: 28790), and "Regulation to Amend Regulation on Medical Laboratories" published in the Official Gazette (date: 4/10/2016, issue no: 29680) modified the Article 34 (2) (Annex: RG-10/4/2016-29680) as follows: "Only the certified, and licenced medical laboratories have the authorization to send samples abroad for testing. Within the coverage of this regulation entry and exit of biological materials of human origin in and out of Turkey is realized only with the permission of the Ministry." When biological materials of human origin are 


\section{TABLE 2. Product development phases

\begin{tabular}{|c|c|c|c|c|}
\hline Research phase & Participant & $\begin{array}{l}\text { Number of } \\
\text { participants }\end{array}$ & $\begin{array}{l}\text { Duration of } \\
\text { the research }\end{array}$ & Objective of the research \\
\hline \multirow[t]{4}{*}{ Phase I trials } & Healthy volunteers & $20-80$ & A few months & $\begin{array}{l}\text { The interaction of the drug within organism is } \\
\text { investigated. }\end{array}$ \\
\hline & If a new drug for cancer & & & \\
\hline & $\begin{array}{l}\text { patients, patients with the } \\
\text { same diagnosis. }\end{array}$ & & & Tolerability to drug \\
\hline & & & & Safety \\
\hline
\end{tabular}

\begin{tabular}{llll}
\hline Phase II trials $\quad \begin{array}{l}\text { The patients with the dis- } \\
\text { ease or condition for which } \\
\text { the drug was developed. }\end{array}$ & $\begin{array}{l}\text { A few months } \\
-2 \text { years }\end{array}$ & $\begin{array}{l}\text { Effectiveness of the drug is investigated. However it } \\
\text { may not be demonstrated with a few patients. }\end{array}$ \\
& Safety data are provided.
\end{tabular}

\begin{tabular}{llrl}
\hline Phase III trials & $\begin{array}{l}\text { The patients with the dis- } \\
\text { ease or condition for which } \\
\text { the drug was developed. }\end{array}$ & 1-4 years & Greater efficacy and safety data are provided. \\
& $\begin{array}{l}\text { Adverse effects seen less frequently in previous } \\
\text { studies may be detected. }\end{array}$
\end{tabular}

Since they are long-term studies, obtained results provide more comprehensive data.

\begin{tabular}{llll}
\hline Phase IV trials & $\begin{array}{l}\text { The patients with the dis- } \\
\text { ease or condition for which } \\
\text { the drug was developed. }\end{array}$ & $>1000 \quad$ Years & $\begin{array}{l}\text { Includes postmarketing studies after licensing the } \\
\text { drug or the device by a health authority. }\end{array}$
\end{tabular}

the drug was developed.

They are postmarketing safety surveillance studies.

required to be sent abroad, according to this article one should be carefull about the licence of the laboratory whether it has or not.

\section{Procurement of a drug from abroad}

"Guideline for Importing Drugs from Abroad and Their Use", PROHIBITIONS ARTICLE 7- (1) Treatments performed in line with the permissions granted by the agency, and the results obtained from them should not be shared with any health institute/organization and/or third parties excepting the Ministry, and they can not be used except for purpose. The data gathered within this frame may be used only by the Institution for scientific publication. Except for these, approval of the Agency should be obtained for scientific publication of the results by other institution/organization (except for "case report"). Still within this frame, these data can not be used as drug licencing data during license application procedures. Those violating the principles of confidentiality are subject to legal action in line with legislation provisions.

To provide drug which are unlicensed in our country from abroad for compansionate use, for the patients who were not be able to treated successfully or cured by licensed available medical products, and who have a serious or life-threatening disease and who can not be included in a related clinical trial, the manufacturer of the $\operatorname{drug}(\mathrm{s})$ can supply the drug for that patient free of 
charge. This can be applied to treatments that performed on outpatient clinics, special clinics and dispensary. The manufacturer is responsible to supply the drug until the drug will be licensed in our country. When the results of the treatment using this drug is to be published, then it should be indicated that the data were derived from a compassionate use program, and they can not reflect a phase trial data.

\section{Clinical investigations with medical devices}

"Regulation On Clinical Investigations of Medical Devices" (Official Gazette date: 6/9/2014, issue no: 29111) prepared based on Health Services Fundamental Law Amended article \#10 published in the Official Gazette (date: 26/4/2011; issue no: 27916) established the issues concerning "Clinical Investigations of Medical Devices" and "Performance Evaluation Studies of In Vitro Medical Diagnostic Devices".

Medical devices are any kind of material manufactured with the intention to diagnose, monitor, treatment, palliation of a disease or those used for contraception which do not exert their basic function via pharmacological, immunological or metabolic effect when they are used on human subjects. They demonstrate their effects through physical or mechanical routes.

Clinical investigations with medical devices constitute of studies performed on volunteered individuals so as to evaluate safety and/or performances of those medical devices.

Only clinical assessments can determine whether a medical device attained the performance claimed by its manufacturer, and whether it is produced in compliance with medical device regulations for health and safety. Clinical assessments should be repeated periodically to obtain new performance, and safety data which may emerge during use of the device.

Every reactants, reactive products, calibrators, control material, kit, tool, equipment, and sample containers designed for in vitro evaluation of biological samples collected from human body so as to obtain information about physiologic or pathologic condition are called in vitro medical diagnostic devices. For these products covered by "In Vitro Diagnostic Medical Devices Regulation", performance evaluation studies should be performed to support, and to validate performance statements related to in vitro diagnostic medical devices.

Marketed medical devices are labeled with a CE mark, and they are registered in Turkish National Pharmaceuticals and Medical Devices Database (TITUBB).
For the ethical consideration of clinical trial with medical devices, the presence of CE label is important.

Clinical Investigations with cosmetic products

For studies of efficacy and/or safety of cosmetic products, and their raw materials, permission from the Department of Cosmetic Products in Turkish Medicines and Medical Device Agency should be obtained according to The Regulation published in the Official Gazette (date: 20/9/2015, issue no: 29481), "Regulation on Clinical trials with Efficacy and Safety Studies of Cosmetic Products or Ingredients".

As is the case with pharmaceutical investigations, in studies performed with cosmetic products, and their raw materials, investigations should be performed firstly on in vitro settings and after established safety profile, cosmetic products or their raw materials may be used in investigations.

Application is priorly evaluated by the Agency, and those that require Ethics Committee approval are referred to the Ethics Committee. Investigations can only be started after obtaining permission of Agency.

\section{Trials with traditional and complementary} medicine applications

In case of clinical trials with traditional and complementary medicine, according to "Regulation on Traditional and Complementary Medicine Applications" published in The Official Gazette (dated 27/10/2014, issue no: 29158), it is indicated that only the listed applications (acupuncture, apitherapy, phytotherapy, hypnosis, application of leeches, homeopathy, chiropraxis, cupping therapy, larva therapy, mesotherapy, prolotherapy, osteopathy, ozon therapy, reflexology, musicotherapy) in this regulation can be investigated in clinical trials. The authority may ask for scentific committee evaluation of current or new applications. The Scientific Commission prepares a report about these applications where, which centers these trials can be performed.

As stated in Article 8, Item 2 of "Regulation on Traditional and Complementary Medicine Applications", for applications not contained in the annex of this regulation (this regulation is related to practices of acupuncture, apitherapy, phytotherapy, hypnosis, application of leeches, homeopathy, chiropraxis, cupping therapy, larva therapy, mesotherapy, prolotherapy, osteopathy, ozontherapy, reflexology, musicotherapy), should be evaluated according to the "Regulation on Clinical Researches on Drugs and Biopharmaceuticals" published in the Official Gazette 


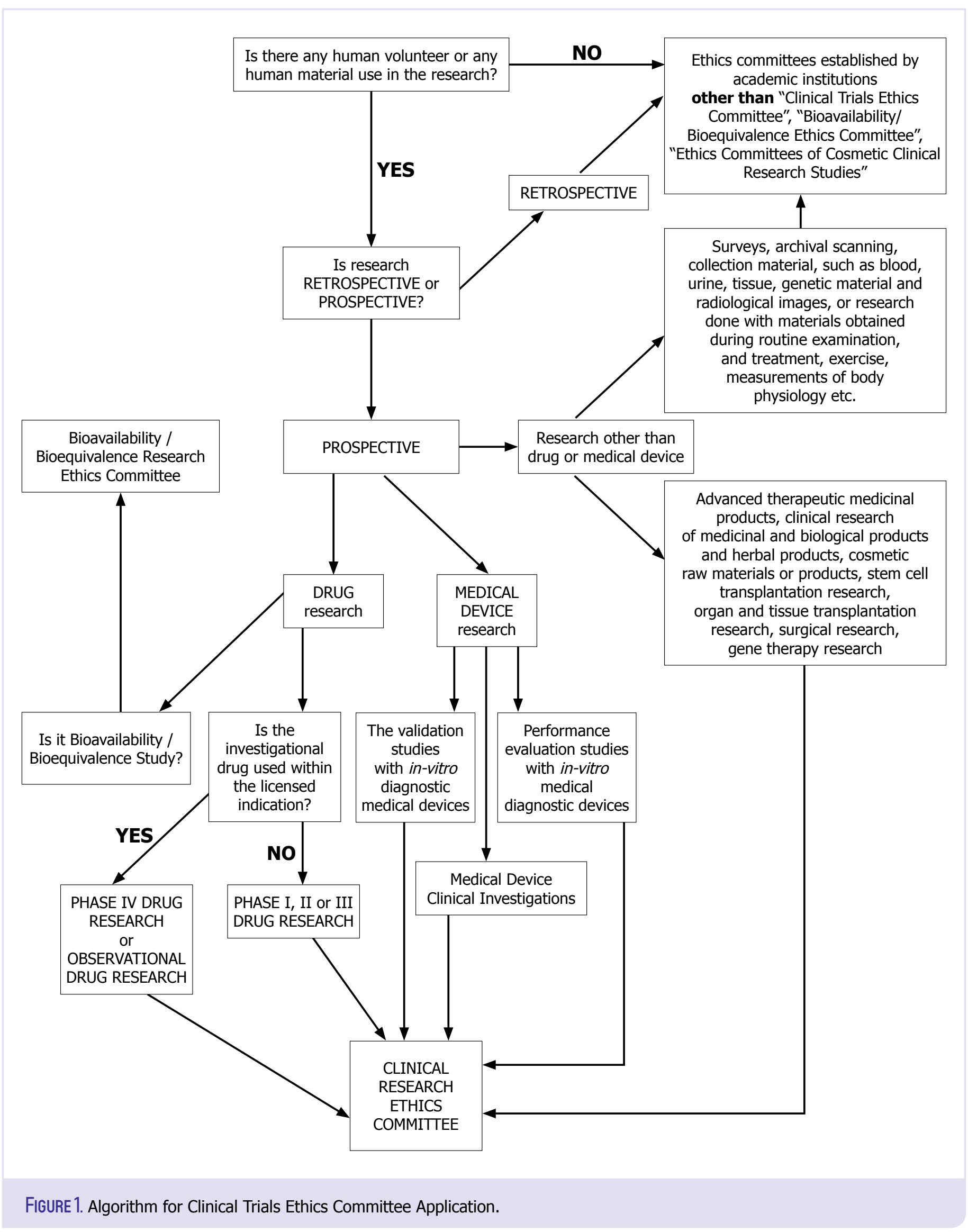




\section{TABLE 3. Checklist of dossier for application to Clinical Trial} Ethics Committee

Application form appropriate for the characteristic of the study Cover letter (Academic research or not)

Permission documents granted by the director of the clinic/unit License of authorization of the research laboratory

Research protocol

Informed consent form

Case report form

Budget form

CV form

Literatures

Information about the research product (research booklet, summary of product characteristics, Instruction manual etc.)

(dated 13/04/2013 issue no: 28617), and researches can be conducted only at application centers, and a copy of the research file is to be sent to Directorate General for Health Services. These studies are evaluated by Scientific Commission as for its contribution to development in country, effectiveness, and level of evidence. These submitted data and studies can not be used without the permission of the individuals and the identity of participants should be confidential. The practices, and related investigations can only be performed in licensed application centers, and by certified researchers after permission of authority.

As stated above, clinical trials ethics committee evaluates research accordingly, but it should be known that commission's final decision will be evaluated by the Scientific Commission in the Directorate of Health Services.

In conclusion, the researchers should fulfill the following requirements, and follow the application algortihm as indicated in Figure 1:

- Have knowledge about the legal regulations.

- Determine whether the research is interventional or noninterventional.

- Decide whether the research is retrospective or prospective.

- Decide whether the research is about a drug, or medical device, or herbal or cosmetic product or other than these.

- Determine the phase correctly, if it is a clinical research.
- Determine the ethics committee to apply accroding to purpose of the study, the collected data and primary end-point.

- Determine the sample size correctly, to determine whether with the specified tools the research hypothesis can be achieved or not.

- Prepare a complete application file (Checklist of dossier is presented in Table 3 ).

Conflict of Interest: No conflict of interest was declared by the authors.

Financial Disclosure: The authors declared that this study has received no financial support.

Authorship Contributions: Concept - H.I., B.T.B.; Design - H.I., B.T.B.; Supervision - H.I., B.T.B.; Materials - H.I., B.T.B.; Data collection \&/or processing - H.I., B.T.B.; Analysis and/or interpretation - H.I., B.T.B.; Writing - H.I., B.T.B.; Critical review - H.I., B.T.B.

\section{REFERENCES}

1. Pollock K. Procedure versus process: ethical paradigms and the conduct of qualitative research. BMC Med Ethics 2012;13:25.

2. Hébert P, Saginur R. Research ethics review: do it once and do it well. CMAJ 2009;180:597-8. [CrossRef]

3. Ezzat H, Ross S, von Dadelszen P, Morris T, Liston R, Magee LA; CPN Collaborative Group. Ethics review as a component of institutional approval for a multicentre continuous quality improvement project: the investigator's perspective. BMC Health Serv Res 2010;10:223. [CrossRef]

4. Akan H. Klinik Araştırmalar Kitabı. Ankara: Bilimsel Tip Yayınevi; 2010.

5. http://www.tdk.gov.tr/. Accessed Apr 26, 2018.

6. Dökmeci İ. Tip Terimleri Sözlügüu. İstanbul: İstanbul Tip Kitabevi; 2011.

7. World Medical Association. World Medical Association Declaration of Helsinki: ethical principles for medical research involving human subjects. JAMA 2013;310:2191-4. [CrossRef]

8. National Commission for the Protection of Human Subjects of Biomedical and Behavioral Research. The Belmont report. Fed Regist 1979;44:23192-7.

9. Council for International Organizations of Medical Sciences. International Ethical Guidelines for Biomedical Research Involving Human Subjects. Geneva: 2002.

10. Ich Harmonised Tripartite Guideline. Guideline For Good Clinical Practice E6(R1) 1996. Available at: https://www. ich.org/fileadmin/Public_Web_Site/ICH_Products/Guidelines/Efficacy/E6/E6_R1_Guideline.pdf. Accessed Apr 26, 2018.

11. Ekmekci PE. Main Ethical Breaches In Multicenter Clinical Trials Regulations Of Turkey. Med Law 2016;35:491-508. 